\title{
Shine a light
}

\section{Marco Bevolo}

\begin{abstract}
Purpose - The purpose of this paper is to report the grounded theory empirical validation on key categories within a design-led methodology to envision urban futures. The paper focuses on the editorial products and the design concepts that constitute the heart of the approach. An original elaboration of trend clusters is presented as an exemplification of the outcome of this trend research approach. Although the approach was not created from the viewpoint of tourism and leisure, bibliographic notes on place-making complement it for this journal.

Design/methodology/approach - The paper presents empirical findings extracted by the means of the grounded theory, with the purpose to empirically validate two key categories (product and process) of a urban futures methodology. The methodology is an application of High Design, the process in use at Royal Philips BV for two decades. This methodology is contextualized within the constructivist episteme, as defined by the editors of this journal in a separate publication. Bibliographic references to place-making complete the paper.
\end{abstract}

Findings - The following findings are provided: empirical validation of the city.people.light communication platform (qualitative research); empirical validation of the city.people.light workshop practice (qualitative research); and bibliographic descriptions of the design process governing city.people.light and newly developed urban futures trend clusters, at European level, as an exemplification of the program/ approach outcome.

Research limitations/implications - The paper is structured according to a multi-layered editorial focus. Empirical findings were generated at primary research level in a 2013-2015 grounded theory projected by the author. Furthermore, the author directed the research processes and products that are the object of empirical validation. Newly defined elaborations and a discussion thereof is offered, taking into account contemporary place-making issues.

Practical implications - The original design-based methodology is a structured practice in urban futures from applied sciences and corporate innovation viewpoint. In this paper, its key categories are empirically validated through the grounded theory. Additionally, outcome from the original foresight programs is presented and a bibliographic review is provided from the viewpoint of place-making.

Social implications - The co-creative methodology herein empirically validated is socio-cultural centered, with a strong drive to coutnerbalance the positivist and engineering corporate mindset through a humanistic concern for people. The framework in terms of place-making takes into account postmodern evolutions of the field.

Originality/value - The paper benefits from a unique mix of: epistemic note on tourism, leisure, and the future; original urban futures scenarios and design concepts from a world class corporate innovation program; and the actual empirical core of the grounded theory validation as performed in a dedicated research project. These three separate streams are mutually related.

Keywords Grounded theory, Design concepts, Lighting innovation, Multipurpose strategy, Strategic design, Urban futures

Paper type Research paper

\section{Introduction}

This paper focuses on a socio-cultural, trend-research-based practice that exists since the mid-1990s, within the portfolio of a lighting manufacturer: city.people.light by Philips Lighting, the Netherlands embracing the socio-cultural complexity of the city as well as its experiential and spatial density. One might essentially describe city.people.light as a multipurpose practice where several activities, including qualitative research and participatory workshops, are complemented by a conscious internal and external networking effort. In the last two decades, such practice has
Marco Bevolo is a Lecturer at NHTV University of Applied Sciences, Breda, The Netherlands and Founder of Marco Bevolo Consulting, Eindhoven, The Netherlands.

Received 30 March 2017 Revised 27 June 2017 16 July 2017

23 July 2017

Accepted 24 July 2017

(C) Marco Bevolo. Published in the Journal of Tourism Futures.

Published by Emerald Publishing

Limited. This article is published under the Creative Commons Attribution (CC BY 4.0) licence. Anyone may reproduce, distribute, translate and create derivative works of this article (for both commercial and non-commercial purposes), subject to full attribution to the original publication and authors. The full terms of this licence may be seen at http://creativecommons.org/ licences/by/4.0/legalcode 
delivered tangible results at brand innovation and strategic marketing levels through its participatory design principles targeting professionals.

The author aims at reporting on an empirical validation of key categories (editorial products as output, workshops as generative process) within city.people.light by means of a dedicated grounded theory project (Bevolo, 2016). In order to support such validation, city.people.light will be introduced and contextualized as a specific urban futures approach, with an editorial product in the form of a book as key communication output. The city.people.light programs, with their methods, tools and intents, were generated in the context of High Design, the general design management process in use at Philips in the period 1991-2011, and not originally applied to leisure or tourism futures. Therefore, High Design will be introduced as well, as a contextual element in the background of this paper.

In order to clarify the focus of this paper, a main research question was defined:

$R Q 1$. How does a design-driven approach work for the purpose of co-creating and communicating urban futures concepts?

In its full-blown scale city.people.light was first performed (1996-1997) by FutureConceptLab, Milan, also identified as the Trends Lab, and Philips Design. Second time (2006-2007), with a ten year hiatus, this program was globally performed with its natural scope of validity. Furthermore, a number of spin-offs or adapted editions, e.g. by scaling down the format, have been designed and executed through the decades. In total, there have been three editions of city.people.light that might be considered representative of the approach: 1996 (global), 2006 (global), initiated by Philips Lighting and executed by Philips Design, and 2011-2013 (European), initiated by Philips Lighting and delivered without involving Philips Design.

In terms of an editorial structure, the paper will unfold from the preliminary sketching of selected references to place-making. This being the context where the approach is applied to the presentation of the methodology itself, and of the grounded theory project designed to empirically review its communication assets (books) and generative practices as structured process (workshops). A summary of concepts from the 2014 Create the Livable City book will be presented. Findings will then be cross-referenced with key issues of place-making, as identified in the bibliographic review, in the "Findings and Conclusions" section.

\section{Theoretical note: the notion of urban place}

Appearing for the first time, an estimated 10,000 years ago, the city might be defined as: "[...] a densely populated entity within a spatially delimited area [...]" (Gottdiener and Hutchison, 2006, p. 21). On this basis, it can be stated that the city is "a place" in terms of its historical, geographical borders, and material perception, given the sociospatial density of urban nature. This is because a city entails the combination of political power, economic functions, and overarching symbolic meanings expressing the deep belief of inhabitants (Gottdiener and Hutchison, 2006, p. 21). Furthermore, a city might just exist in people's minds, in terms of vicarious experiences (e.g. its image in movies, books, media and other communication channels, including face-to-face or mouse-to-mouse exchange) (Govers and Go, 2009). Therefore, the city is actually more than a "place," since a city might be interpreted both as statically manifested at a given moment in time and dynamically shaped over time, in people's minds.

Quinlan, Cutler and Carmichael summarize the tourist experience from people's perspective (Morgan et al., 2010, p. 8), where only two constituencies pertain "places," namely the "Physical Aspects (Influential Realm)" and the "On-site Activities (Tourist Experience)." Based on the extensive review of definitional sources on the topic, Quinlan, Cutler and Carmichael (Morgan et al., 2010, p. 5) identify 13 categories, from "Phases of Experience" to "Overview of tourist experience research areas," with only one being focused on places, namely "Places and mobility." Whilst not totally neglected, spatial considerations might not appear as prominent in the field of tourism studies. However, this is complemented by the rich texture of sources from other fields, e.g. leisure studies, social sciences and of course the domains of place branding or urban design. Here, the "making of places" beyond hardware might be seen as an emerging - or even a central - topic in terms of both intellectual challenges and economic relevance. Exploring notions of "place-making," 
Richards (2017) proposes a theoretical reflection that goes from the American urbanist movement, where "places" were regarded primarily in spatial or architectural sense, to Levebre's (1974) Production of Space, where symbolic spaces and lived experiences do acquire an important role in the making of places. As stated by Lefevbre (1974/1984): "To produce space: [...] Consider the case of a city - a space which is fashioned, shaped and invested by social activities during a finite historical period. Is this city a work or a product?" (p. 73). A city is constantly in the process of (self)-development in history and context, through both its design and its everyday practices. The challenge is, therefore, to identify a conceptual representation of place-making processes that might capture such complexity; however, with the necessary synthesis. Analyzing Lefevbre, Soja (1996) proposes the "Trialectics of Being," an ontological model encompassing historicality, spatiality and sociality as the constituencies of "being" (Soja, 1996, p. 71). Furthermore, Soja notes the necessity of: "[...] the reassertion of Spatiality [...]" (Soja, 1996, p. 71). From this theoretical construct, Soja consequently defines a "Trialectics of Spatiality," comprising: "Firstspace epistemologies," referred to: "[...]objectivity and materiality, aiming towards a formal science of space" (Soja, 1996, pp. 74-5); "Secondspace Epistemologies," referred to: "[...] the interpretative locale of the creative artist and artful architect, visually or literally re-presenting the world [...] the utopian urbanist seeking social and spatial justice [...]" (Soja, 1996, pp. 74-79); and "Thirdspace Epistemologies," referred to: "[...] the sympathetic deconstruction and heuristic reconstitution of the Firstspace-Secondspace duality[...] what Lefevbre once called the city, a "possibilities machine [...]" (Soja, 1996, pp. 71-81). Richards (2017) elaborates on Soja's "Thirdspace" and what clearly emerges is the hypothesis that place-making pertains both a spatial (or static) constituency and a socio-cultural (or dynamic constituency). This is where the tourism and leisure perspectives on "place" might be positioned in the future. This is also where the design-led approach as presented in this paper might be discussed and positioned.

\section{Epistemological note: futures research and design}

Be it in the form of Delphi oracles or horoscopes "the future" has represented both a tension and a question since the origins of culture. From an epistemological point of view, the future and the past share the indeterminate nature of their being, in the present. Both are based on a reconstruction of events that either did happen or might happen, under context and circumstances that either do not exist any longer or do not exist yet and on the basis of extrapolation from single documental evidences or from detected trends, whereas the study of the past has been codified for centuries in the methodologies and philosophies of history (Staley, 2007). Concurrently an equivalent codification of futures research has only existed since the last century (Bevolo, 2016). Such institutionalization has resulted in a formal codification of the fields of future studies and foresight and ultimately of what a "futurist" is.

Within the context of global corporate enterprises, "foresight" has been adopted as a strategic portfolio competence since the end of the Second World War. This has led to anticipate future change and emerging lifestyles. Topical moments include the availability of alternative scenarios unveiling "wild card" possible - however unlikely - events at Royal Shell. The oil company that uniquely anticipated - before 1973 - the end of abundance in oil supply. Within this paper, a constructivist definition was identified and is adopted from tourism futures literature: "Futurists never present objectivity but a range of alternatives of subjectivity. The research they are involved in presumes interpretation which Schwandt (1994) labels constructivist interpretation. This is an ontology that is predominantly local and specific in which the creation of knowledge is grounded in practice. This epistemology views knowledge in a subjective and transactional manner as merely suggesting directions along which to look, rather than providing descriptions of what to see [...]" (Yeoman, Postma, Oskam, McMahon-Beattie, Findlay, in Postma et al., 2013, p. 60). This definition of "futurist" was crafted by its authors in the context of a major study of European tourism futures. It resonates with the notion of design in the context of history that Flusser proposes, a notion where "[...] all forms are temporal" (Flusser, 1999/2009/2010, p. 61). In Flusser's work, the relationship between "design" and "future" is embodied in the archetype of the architect/engineer. This is based on their ability to anticipate what the future will bring, to draft solutions accordingly, to plan actions and make it happen, over time, starting from their insights and ideas, captured in concepts and drafted in sketches. 
The paramount relevance of sketching within engineering, architectural, and design processes might respond to a historical trait of the architectural profession, going back to its intellectual inception in the 1500s: "The command of drawing - not building - unlocked the status of the architect, establishing the principle that architecture results not from accumulated knowledge of a team of anonymous craftsmen but the artistic creation of an individual [...] Asserting their intellectual status, architects made drawings with just a few delicate lines and imagined buildings that were equally immaterial" (Hill, in Fraser, 2013, p. 15). Design sketches are visual representations of concepts that capture experiences and objects yet to come, envisioning possible futures, in the present. Concepts potentially trigger processes of meaning-making that will impact the course of events. The generation of concepts might take place as the output of individual creative processes, or by means of constructivist participation. As opposite to individual "genius forecasting" and as an advanced form of dialogues by co-creation, the workshop format has been historically identified as an eminently participatory methods of generating future visions by means of facilitation (Jungk and Muellert, 1987). In the next paragraph, it will be articulated how the urban futures methodology at the heart of this paper might meet a number of the above generic principles, leveraging its visual output as the outcome of generative workshops.

\section{Methodologies: design process and reflexive validation}

In order to document outcome and operationalize validation of the above, this "Methodology" section is articulated as a hybrid mix. It combines the design methodology "behind" city.people. light, namely High Design, and the qualitative research methodology that enabled a grounded theory validation "of" city.people.light, as its research object. These two distinctive topics will entail descriptive sub-sections (Sections 4.1, 4.1.2 and 4.1.3), aimed at presenting the background of city.people.light, while introducing two validation key categories. Concurrently, in Section 4.1.1, operational information will be provided about the grounded theory empirical process. To fulfill its hybrid nature, these methodological paragraphs will be editorially divided in two modules, addressing:

4.1: a bibliographic investigation dissecting the overall High Design process that underpins the approach at hand as a process framework and a discussion of how it was applied to urban futures;

4.1.1: the grounded theory operational references for the empirical (reflexive) validation of city. people.light (Bevolo, 2016), including specification of the key categories;

4.1.2: a bibliographic presentation of the Key Category 1: workshops; and

\subsection{3: a bibliographic presentation of the Key Category 2: books.}

Within this paragraph, city.people.light plays different functions: in 4.1 High Design clarifies the governing process of city.people.light (therefore, a generic design process is presented, of which city.people.light is one application), whereas in 4.2 , grounded theory enables the study of city. people.light as research object. The grounded theory being the key operational reference for this paper in empirical terms.

\subsection{Design process framework - High Design: a co-creative approach to envision urban futures}

"High Design" is the reference governing principle for city.people.light programs. High Design was in use at Royal Philips NV in the two decades 1991-2011 as a future-oriented corporate design process. It can be defined as follows: "High Design is a human-focused, research based, design management process for repeatable business success. High Design integrates the input from socio-cultural disciplines and people research, and then makes that information and insight the starting point of every design project". High Design principles were integrated in a universal design process, in order to offer a flexible and scalable mix of creative and strategic competences addressing the wide portfolio of Philips businesses (urban lighting, lighting, consumer electronics, domestic appliances, medical systems, computing devices, semiconductors and components). Such principles are applicable both to innovation processes and challenges (Kusume and Gridley, 2013) as well as brand marketing (Bevolo and Brand, 2003). Hence, offering an optimal 
degree of flexibility and versatility across future-oriented challenges. Its application was then expanded to design-led partnerships with lifestyle brands such as Levi's and Nike (wearable technologies), and other non-Philips non-competitive customers. For example, the Municipality of Eindhoven with their Strijp-S lighting experience strategy, directed by Lorna Goulden, published in an award winning book (2008) modeled on the city.people.light format. One peculiar feature of High Design is its ambition to generate "Co-creation Communities" (Kusume and Gridley, 2013, pp. 55-6). This lies in the inclusive recognition of each stakeholder as an acceptable/accepted contributor. Therefore, High Design programs might aspire to create "an open community," focusing on informal dynamics and knowledge in the "fuzzy front" of innovation (Rameckers and Un, 2005, pp. 11-4).

Shifting from the generic corporate design/foresight description of High Design as a governing principle to the specific city context, its derivative application for urban outdoors is identified as city.people.light. Namely, a future research approach should be with the following qualities: design-led, participatory, visual and socio-cultural-focused. Its purpose is to enable and underpin participatory lighting innovation processes over time. From a formal point of view, one should stress the fact that the nominal validity for city.people.light outcome is conventionally perceived at half a decade to a decade ahead in the future, with industrial innovation processes aligned to this time frame. A typical city.people.light cycle historically may have lasted for five years. This comprises a qualitative research project or a series thereof, based on interviews with thought leaders and decision makers in city management and urban architecture; a number of workshops, involving lighting design professionals at regional level; the processing, editing and publication of outcome in the form of highly visual books and their valorization in conferences and lectures; the analysis, clustering, and activation of specific concepts in the corporate strategic marketing and innovation funnels; the academic valorization and networking exploitation of outcomes, with commercial focus of relationships. Qualitative research is leveraged as a source for the writing of scenarios. Such scenarios are based on prefigured coded insights. The coding is performed by first elaborating insights from qualitative interviews and then filtering them through a dedicated Urban Futures Matrix. Such tool connects socio-cultural drivers, therefore representative of longer term futures, with city strategies and therefore modalities of organizing urban realities. The resulting scenarios are at the same time the formal end deliverable of qualitative research and an ancillary asset to support the abductive processes of future visioning by architects, designers, and other workshop contributors, who lead in this process. Scenarios are fixed as a given narrative asset in the process. They inspire workshop participants to co-create "Design Concepts" by means of facilitated dialog and discussion. Design Concepts are therefore at the heart of the output of participatory practices. An overview of 2014 Design Concepts will be presented in Section 4, summarized in clusters. It must be specified that scenarios do not represent the main focus of this paper. Therefore, a historical or critical discussion thereof will not be presented.

4.1.1 Reflexive validation: grounded theory methodology operationalization. A dedicated grounded theory project (Bevolo, 2016) was designed in 2013 and executed through 2015, with the purpose to validate this urban futures approach. For this purpose, city.people.light communication outcome, in the form of books, and city.people.light generative practices, in the form of workshops (with Design Concepts as output), were identified, described and analyzed as key categories of investigation. First, such workshops were investigated as grounded theory research objects (Bevolo, 2016):

- Creation process of (urban futures) scenarios and concepts, with a key category focusing on the "workshop" as process designed to enable professional stakeholders and members of relevant communities of practice to generate city.people.light findings (grounded theory validation - Key Category 1).

- By "workshop" it is herein specifically identified the stakeholder-focused, co-design aimed, facilitated event (format and execution) as performed in the city.people.light programs performed in 2006 (globally) and 2011-2013 (Europe), based on the overall managerial decision-making.

- Second, the central role in terms of outcome is played by editorial products that regularly report and diffuse research program findings, concepts and all necessary information,

VOL. 3 NO. $22017 \mid$ JOURNAL OF TOURISM FUTURES $\mid$ PAGE 175 
e.g. bibliographies and references. The books were therefore strategically positioned as structural moments in the process. In this respect, their function as communication products were clarified and formulated as a precise grounded theory research object (Bevolo, 2016).

- Communication of (urban futures) scenarios and concepts, with a key category focusing on the "book" as a product designed as a structural moment to channel and communicate city. people.light findings (grounded theory validation - Key Category 2).

Based on the above starting points, the grounded theory analysis (Bevolo, 2016) relied on the following assets:

- 13 interviews with qualified respondents performed in November/December 2013 (not included here: details of qualitative research participants);

- extant documents, as reference examples of concrete managerial practices determining the workshop design and execution;

- photographic records of six published workshops (2014);

- video recordings of city.people.light class events held in 2011-2013 (Bratislava, Turnhout, Dubrovnik, Copenhagen, Glasgow);

- professional memo's supporting the contribution by the researcher to 2011-2013 workshops, in his capacity of consulting research principal commissioned by Philips Lighting BV;

- personal memories (memoire) and anecdotal evidence from city.people.light 2006 and 2011-2013 workshops, including e-mail transmissions and other company confidential documentation;

- presentations, trade articles and other collateral assets describing the process and its structural or practice-focused constituencies for promotional or other official purposes;

- book as published in 2007 with design sketches and analysis;

- book as published in 2014 with design sketches, photographic materials and analysis, including philology of concepts related to 2007;

- transcripts of 13 thought leader qualitative interviews 2006;

- transcripts of eight thought leader qualitative interviews 2011-2014; and

- presentations, trade articles and other collateral assets, generated between 2006 and 2015.

The 13 interviewees were selected according to the principles of "purposive sampling" in a homogeneous professional culture (Guest et al., 2006, p. 61). Therefore, as verified by accomplishment of saturation, this selection met the validity requirements for satisfactory performance of qualitative research. The interview transcripts were edited by each participant in terms of their review and approval and then framed through a number of analytical steps at various levels of coding aggregation. Key findings (as defined at the stage of Open Coding within the grounded theory project) for this "reflexive" component of this paper will be presented and commented on in the "Findings and Conclusions" section.

4.1.2 Grounded theory validation - Key Category 1: a review of workshops as the heart of the approach. Within High Design, workshop design and management are specific techniques aimed at facilitating teamwork in dedicated sessions, with the objective to generate a shared space of safe dialog and productive exchange for the co-creation of ideas, concepts and solutions through a process of communal understanding and mutual acknowledgment across different and diverse stakeholders. Facilitation entails the creation of optimal enabling conditions for participants to perform. From white sheet to the final concept, they re-connected their work to urban futures hypotheses presented as qualitative research findings. By setting up a non-competitive, non-commercially purposed, communal "space of communication and collaboration," city. people.light organizers and facilitators historically managed to gather competing architects, competing designers and administrative officers from sometimes competing cities, and enable them all to systematically reflect and co-create as members of temporary teams. A typical city. people.light workshop entails one to two days of communal working sessions, starting from the 
presentation of qualitative research findings. Stakeholders are invited to assume a participatory, proactive role, in order to envision and deliver their ideas of future urban lighting in the form of design sketches with the availability of professional illustrators to immediately fix ideas on paper. Ideas and sketches are articulated into concepts with a critically discussed link to scenarios. Scenarios are systematically presented as qualitative research findings. Concepts are then optimized in a narrative form, completed by a specific title.

A crucial probing point for city.people.light concerns the inclusion of ordinary citizens in workshops or other forms of participation. The answer to such point is negative because city. people.light is a Business-to-Business program within a corporate context. Critical elaboration on this point might indicate a fit with what Verganti and Pisano describe as the "Elite Club" modality of co-creation for corporate enterprises (Pisano and Verganti, 2008, pp. 78-86). This is an "open innovation" approach that only entails the involvement of restricted circles of selected professional contributors only. This consideration clarifies the relatively limited scope and non-existing direct impact of the program design from an Action Research viewpoint, especially from the viewpoint of political implications. Simply put, city.people.light programs have not been conceived or designed as "social innovation" opportunities for urban communities. At the same time, however restricted to a specific professional community, one cannot deny the co-creative nature of this approach, its process design and its immediate output.

4.1.3 Grounded theory validation - Key Category 2: a review of the book as communication asset. The process as described above repeatedly led to a selection of "urban futures ideas" visualized in appealing sketches or photographic reproductions, to be collected, edited and presented to the wider public in a book format (Bevolo et al., p. 2007). At the end of every cycle, the outcome of a number of coherent and comparable workshops is analyzed, processed and edited into an appealing publication. In such communication format, the design and editorial lines of city.people.light books privileged sketches and visual assets as a vehicle of representation of future concepts. This conscious editorial choice, and the very selection of the "book" as privileged communication tool, might find their ultimate roots in those cultural discourses rationalizing how architecture historically emerged from craftsmanship as a higher cultural enterprise.

In this paper, references are dual, to both the 2007 and the 2014 books. The editorial architecture of the two products is similar with an opening part related to urban futures: Urban Trends (pp. 8-21, in 2007) and Urban Futures (pp. 11-35, in 2014). The 2007 architectural thought leaders, e.g. ranging from Richard Rogers to Odile Decq, from Hans Hollein to Robert Venturi and Denise Scott Brown were presented in more prominent fashion than the 2014 European experts. The 2014 European experts covered architectural firms (Piber, Bantal), city management department (Urbanowicz, Johnston), academia (Mommaas) and the field of urban leisure (Mommaas, Verri, Korkman). It might also be relevant to mention that the 2007 book was referenced at the introduction of every 2014 concept. The editorial and research goals were to ground 2014 manifestations in historically antecedent "weak signals," hence creating a visible degree of continuity and coherence across two different editions of the program, managed by means of equivalent process and formats.

Focusing on the visual sections of the books, where co-created Design Concepts are presented, the 2006 sketches from global workshops (Lyon, Philadelphia, Shanghai, Hamburg) were introduced as "Inspirational." The editorial section consisted of double-spread pages reconnecting the different regions to the original expert interviews, with unattributed quotes (pp. 28-9, 66-7, 90-1, 122-3, 2007), complete with the lists of workshop participants. The 2011-2013 sketches and their related mock up photographs were introduced with an overview of the six cities involved (Bratislava, Copenhagen, Turnhout, Dubrovnik, Wroclaw, Glasgow) (pp. 38-9, 2014) and by an organic overview of design and organizational issues related to the workshops themselves (pp. 40-1, 2014). At the end of the book, the 2007 conclusions were limited to one page (p. 150, 2007), under the programmatic title: "Open conclusions for a program that will never end". Thus, deliberately stating the intent not to supply any conclusive remark as a way to interpret its nature of "open platform." The 2014 conclusions provided, instead, four directions, articulated in 16 questions corresponding to the 16 cells (or scenarios) in the referenced Urban Futures Matrix, adopted throughout the process. Therefore, "wrapping up" the entire book from the perspective of 
this specific research and workshop governing tool (pp. 153-5, 2014). These formats adopted to deliver conclusions might be perhaps described as key points of divergence of this approach from the positivist posture, demanding specific findings to answer a specific research question. Whereas the positivist reader might find this indeterminacy unpalatable, the postmodern design research will appreciate it as inspirational.

\section{Design concepts as output: a summary by clustering}

It was anticipated both in the Notes and in the Methodology above, how Design Concepts are the results of co-creative workshops. Design Concepts could therefore be considered a key product within city.people.light as a High Design application. A presentation of Design Concepts will be herein provided with the goal to illustrate them, namely with the purpose to present the output of workshops as well as get a visual insight into the content of books. Design Concepts are of course not the result of grounded theory validation as conducted by means of qualitative research on the two Key Categories above, workshops and books. The latter will be presented in the final section, "Findings and Conclusions."

As so far introduced concepts are the outcome of co-creative workshops, where scenarios are presented and shared, to be activated within dialogs as part of a facilitated process where the primary focus is on idea generation by workshop participants. Additionally, it must be specified that concepts were generated by multidisciplinary, multicultural teams with regional focus, as generic and universally applicable. Design Concepts and sketches were therefore only spatially related to any specific location, as they had the main ambition to generate visions of urban futures at the general level. Because of their specific category focus on the night-time and on lighting, city.people.light concepts did extend to mobility, lifestyle, leisure or other domains, both in their actual topics and themes, as well as in their application and valorization.

A key source for this summary is one book, Create the Livable City, published by EMAP/AJ Books in 2014. The book was co-authored by Tapio Rosenius, MSc, and the author of this paper, as valorization of the European program for strategic marketing and innovation commissioned by Philips Lighting EMEA in the triennium 2011-2014. Featured assets include the visual and textual report of six co-creative workshops with professionals. Each concept was visually presented in the context of its specific city event. Every concept was then edited with "Lighting design notes" at the technical level and visualized by means of both sketches and photographs, representing mock up installations co-created during the workshop, each with a specific title. For presentation and synthesis purposes within this paper, concepts were summarized in trend clusters, offering new original aggregations and themes. Each trend cluster will be introduced by means of a reflection on spatial traits shared by individual concepts.

\subsection{Trend cluster: natural artificial}

Across workshop locations a new sensibility emerged based on reconnecting to nature by means of signs and symbols generated by digital or architectural solutions. From a spatial point of view, the integration of lighting technology and infrastructure enables the creation of visual effects to represent the memory of nature "as it was" before urbanization (e.g. the original grass under the pavements or the water of the sea on the floor of a courtyard divided from the Mediterranean by an ancient wall). One concept proposes the transformation of the green decorative frame around a martial square into the focus of the square itself, whereas the monumental pedestal at its center shifts from a displaying a military statue to focalizing two beams of light in the sky, as a symbolic way to reconnect it to the trees and flowers. Here, a modest urban garden becomes a visual poetic symphony, magnifying the role of nature to requalify this underprivileged square. Just one step further and leisure objects and buildings are giving night-time "pulse" and vibe to the city. For example, discotheques or clubs are repurposed to represent environmental themes through ambient experiences. This might be a major step in terms of integrating the symbolic representation of nature into contemporary lifestyles. According to these references future developments in the city might culturally encompass a deeper drive to reconnect to nature, even in its most primordial form. 


\subsection{Trend cluster: abstract narratives}

From a spatial perspective, within this second aggregation of co-created trend manifestations infrastructural and architectural hardware is elevated to the role of narrative trigger. This is first articulated at the level of minimal/minimalistic esthetic intervention on bridges or mixed programs. Thus, storytelling is enabled as a loose and indefinite intellectual parcour across abstract points, embedded in lighting solutions that enliven what used to be dark infrastructure. Similarly, abstract storytelling is also the creative approach chosen for the concept based on projections on the internal façade of the Rector's Palace in Dubrovnik, where the story of the city is translated, by music and light, into an abstract sequence of effects and experiences. Concurrently, such narrative approach co-exists with the iconic approach adopted for historical elements such as the stone stairs in the same courtyard of the Rector's Palace. The workshop participants treated this object in context as a semiotic device enabling access to multipurpose leisure programs to be located on the first floor, from fine arts to a casino. Lastly, wrapping up esthetic themes of the whole trend cluster, an otherwise loose sequence of architectural design elements, becomes the texture of a narrative analogy to Dante's Divine Comedy, in an elegant Glasgow concept. Completely void of any connection to social or personal sustainability concerns, this trend cluster appears less compact and more nuanced than "Natural Artificial." Concepts spread across leisure programs and tourism activities with priorities spanning from city beautification to cultural tourism and decorative storytelling to the management of space and place.

\subsection{Trend cluster: spatial socialization}

This trend cluster entails diverse spatial nuances and executions, with multiple faceted directions in both esthetic terms and design opportunities. First, fine arts are present in terms of objects or lighting solutions. Here triggers stimulate individuals to gather, share and communicate. This is the case of the virtual "orange bonfire" that became the signature visual of the book cover. Next to this artistic direction, advanced technologies play a role in terms of transforming analogue surfaces like windows into contextual social media at local level or in enabling an evolution of the speaker's corner into new digital opportunities, once again for aggregation and gathering. On a more functional level, in a Silesian vernacular manifestation of both esthetics and urban design, the dynamic lighting treatment applied to a pedestrian underpass transforms a dark tunnel, where citizens do not dare to walk at night, into an informal playground for kids. Here, the social representation of re-appropriation of an otherwise blocked urban corridor is represented by the spontaneous socialization of children in joyful play. Lastly, with a more conventional leisure and tourism approach, the repurposing of industrial stock into communal facilities for migrants or for plain relaxation purposes is also featured, with a particular prominence of communication and exchange as programmatic societal purposes. As a synthesis, in this trend cluster 1 might say that both new and long-term citizens are enabled to exercise the right to self-expression. Publicly, gathering as individuals to learn, exchange or transact, in the context of new forms of leisure experiences.

\subsection{Trend cluster: functional planning}

This final "minority cluster" groups two concepts that are loosely connected by the functionality focus of their scenarios. One might highlight the eclecticism of postmodern planning, where contemporary forms and materials join ancient esthetics without rejecting them. Lighting plays a more ancillary role, enabling the design or the fruition of urban places for specific purposes and with ease of use. Simplicity of interaction is key, with spatial focus on architectural styles or functional performance. From an experiential point of view, solutions based on this minor socio-cultural cluster might support the design planning of an intuitive city, that will be open and appealing for visitors by design.

\section{Findings and conclusions}

\subsection{Grounded theory validation: preliminary empirical findings}

Within the grounded theory empirical validation of city.people.light (Bevolo, 2016), the "workshop" process as practice-based moment of co-creation was empirically described by a 
number of items and qualities, including the following preliminary overview capturing interview recurrent topics and themes by means of Open Coding:

1. thought leadership-focused events with multipurpose nature (relationships, innovation);

2. events where insights are generated in order to populate product roadmaps;

3. events conceived and governed by means of a "Design Thinking" mindset;

4. lighting design focused session;

5. events inspired and managed by means of the urban futures matrix;

6. events integrated in an implicit city.people.light brand theme;

7. educational value events, perhaps beyond the internal perception at Philips;

8. sketches maintain a central role in the conversion from theory to concepts;

9. offering the opportunity to perform wild cards and blue-sky concepting; and

10. not based on technology, however depending on the existing technology for mock ups.

The key performance indicators, or equivalent, connected to the workshop format as adopted in this process were identified as follows:

1. measurement of performance mainly assessed by Net Promoter Score (a CRM tool, since 2011) (Reichheld, 2006);

2. conversion of workshop outcome into solution roadmaps (two to three product ranges over five years);

3. generically expected 1-5 percent conversion rate from sketches to product ranges;

4. indirect CRM conversion expected in terms of future commercial opportunities; and

5. financial and commercial value questioned and challenged by internal stakeholders.

The core of the program output and its main communication platform lie in editorial products, visually reporting Design Concepts as related to qualitative research findings and other knowledge assets. Concepts are presented as outcome of workshops within a socio-cultural analysis framework, with bibliographic references and with sketches and photographic depictions of possible urban futures with universal validity, hence non-specific to the city where they were generated. At the level of grounded theory empirical validation, the book as a research object was described in accordance to a number of points extracted by semantically analyzing transcripts and conducting Open Coding; including the following early findings:

1. thought leadership content, focused on future solutions;

2. visualizations based on insights;

3. visualizations aimed at playing an inspirational function;

4. visualizations expressed by means of sketches;

5. content based on critical mass of workshop output;

6. source of functional knowledge and somewhat monitoring;

7. based on structured analytical semi-academic knowledge;

8. technical knowledge;

9. based on research; and

10. falsifiable, as based on the urban futures matrix.

The key performance indicators that implicitly determine the perceived quality of the book as output format of this approach were identified as follows:

1. publication of architect's interviews;

2. interaction with the target audience; 
3. conversion of selected content into solutions roadmaps;

4. PR visibility on a specific brand theme; and

5. leadership in the market.

The general storyline is one of education and inspiration for relevant target audiences, based on critical urban challenges. Visualizations preponderantly lead in the editorial and communication strategies, being perceived as the most relevant feature of the books. The esthetic and sensorial core visual manifestation of both 2007 and 2014 books is based on co-created concepts (sketches and photography) (the latter in 2014 only) and in workshop sessions.

\subsection{Conclusions on the program as high design application}

The city.people.light approach described in this paper is intrinsically multipurpose. It was born in the industrial context to support corporate processes of design, innovation and strategic marketing, High Design offers the opportunity to deliver multiple assets to product innovation processes, thought leadership profiling and a number of strategic positioning platforms in the company, and beyond. Strategies are implicit statements about preferred futures, whereas future research embodies a range of possibilities yet to come. Furthermore, the future might be influenced by actions taken in the present, including participatory dialogs and communication of potential developments, e.g. in the form of "posits" (or concepts) that "stand for" what might come. In particular, one might speak of this approach as a constructivist approach for an "Elite Club" of selected professionals, who partake in an open innovation process. Here, they are invited to co-create hypotheses deemed to envision the future of a particular field, the city, from a socio-cultural viewpoint, at night and with focus on outdoors environments. Citizens are not directly involved, by managerial choice. The process is based on design research principles, with qualitative research at its basis and workshops as generative moments of practice. The program is executed by means of regional events, in selected cities, with participants from the architectural, city management and lighting design sectors. Given the specific constructivist, co-creative and design-led nature of the approach researched in this paper, it might be important to avoid any misunderstanding possibly generated by any (rigid) interpretations of its content from a positivistic perspective. While the design methodology at hand might be described as business oriented and utilitarian, it was born in the early 1990s as a way to create a formalized substantial juxtaposition to positivist notions of "science," and their technocratic translations of assets into technological roadmaps for top down deployment into markets. One might say, that the very nature of city.people.light is complementary, if not antagonistic, with respect to positivistic notions of linear forecast and technological road mapping.

In conclusion, without aiming at a validated and calibrated assessment from theoretical or epistemological viewpoints that would exceed the purpose of this paper, a working hypothesis for potential next steps in the analysis of this approach is that city.people.light narratively presents the city (of the future) as a "possibilities-machine" (Soja, 1996, p. 81). As a conclusive framing, according to the categories proposed by Soja in his "Thirdspace" (1996), this approach might be described as a creative reaction again "Firstspace epistemologies." It was developed and delivered with the ambition to counterbalance scientific positivism and engineering roadmaps as leading business drivers within Philips Lighting. Therefore, it might be tentatively proposed that this approach resonates with "Secondspace epistemologies," as it delivers visualizations developed through interpretations and insights of architects, designers and other professionals, who re-present possible worlds, in terms of night-time urban futures. Hence, this might comprise of both static and dynamic dimensions of place-making as described by Richards (2017). The future orientation and socio-cultural focus of city.people.light might extend its reach as it addresses spatial challenges from people's perspective, although through the professional eyes of architects, designers and other selected participants. At least from its specific angle of innovation design, it might find a potential affinity with the tourism studies "experience area" of "Places and mobility," as previously identified. Furthermore, the socio-cultural angle implicitly acknowledges the relevance of social activities as a shaping force of the city, possibly in line with Lefevbre's (1974/1984) considerations on the complexity of the production of space. 
It might, therefore, be proposed as a final reflection that city.people.light has traits and characteristics responding to and fulfilling (at least to an extent) what postmodernist place-making theory asserts. Hence, possibly playing a role in addressing research challenges from postmodern viewpoints of tourism, leisure and urban design.

\section{References}

Bevolo, M. (2016), "The role of design in generating urban futures", PhD thesis, Tilburg University, Tilburg.

Bevolo, M. and Brand, R. (2003), "Brand design for the long term", Boston, Design Management Journal, pp. 33-9.

Flusser, V. (1999/2009/2010), The Shape of Things. A Philosophy of Design, Reaktion Books, London.

Fraser, M. (Ed.) (2013), Design Research in Architecture. An Overview, Ashgate, Farnham.

Govers, R. and Go, F. (2009), Place Branding, Palgrave Macmillan, London.

Gottdiener, M. and Hutchison, R. (2006), The New Urban Sociology, Westview, Cambridge, MA.

Guest, G., Bunce, A. and Johnson, L. (2006), "How many interviews are enough?: an experiment with data saturation and variability”, Field Methods, pp. 18-59.

Jungk, R. and Muellert, N. (1987), Future Workshops. How to Create Desirable Futures (English Translation 1996), Institute for Social Inventions, London.

Kusume, Y. and Gridley, N. (2013), Brand Romance. Using the Power of High Design to Build a Lifelong Relationship with your Audience, Palgrave, Basingstoke, Hampshire.

Lefevbre, H. (1974/1984), The Production of Space (English Translation 1991), Blackwell, Oxford.

Morgan, M., Lugosi, P. and Ritchie, B. (Eds) (2010), The Tourism and Leisure Experience, Channel View Publications, Bristol.

Pisano, G.P. and Verganti, R. (2008), "Which kind of collaboration is right for you?", iHarvard Business Review, December, pp. 78-87.

Postma, A., Yeoman, I. and Oskam, J. (2013), The Future of European Tourism, Stenden University of Applied Sciences, Leeuwarden.

Rameckers, L. and Un, S. (2005), "People insights at the Fuzzy Front of Innovation. How to achieve human-centered innovation", presented and Nomitated Best International Paper, ESOMAR, "Qualitative Conference".

Reichheld, F. (2006), The Ultimate Question, Harvard Business School Press, Boston, MA.

Richards, G. (2017), "From place branding to placemaking: the role of events", International Journal of Event and Festival Management, Vol. 8 No. 1, available at: http://dx.doi.org/10.1108/IJEFM-09-2016-0063

Soja, E.W. (1996), Thirdspace. Journey to Los Angeles and Other Real-and-Imagined Places, Blackwell, Oxford. Staley, D.J. (2007), History and Future. Using Historical Thinking to Imagine the Future, Lexington Books, Plymouth.

\section{Further reading}

Anholt, S. (2007), Competitive Identity, Palgrave, London.

Bevolo, M. and Rosenius, T. (2014), Create the Livable City, AJ Books/EMAP, London.

Bevolo, M. (Ed.) (2007), city.people.light, Philips Lighting, Eindhoven.

De Certeau, M. (1984), The Practice of Everyday Life, University of California Press, Berkeley and LA, CA.

Dinnie, K. (Ed.) (2011), City Branding, Plagrave, London.

Kuosa, T. (2012), The Evolution of Strategic Foresight, Gower, Farnham, Surrey.

Richards, G. and Russo, A.P. (Eds) (2016), Reinventing the Local in Tourism, Channel View Publications, Bristol.

Richards, G. and Smith, M. (Eds) (2013), Routledge Handbook of Cultural Tourism, Routledge, Abingdon, Oxon. 
Slaughter, R. (1995), The Foresight Principle, Adamantine Press, London.

W. AA (1997), city.people.light, Philips Lighting BV, Eindhoven, ISBN 90-801262-2-5.

W. AA., Goulden, L. et al. (2008), Strijp-S. Creating a Public Lighting Experience, Royal Philips Electronics NV, Eindhoven.

W. AA., Olcanto, R. and Van der Linden, J. (2013), "Learning from glas vegas. An aj design charrete philips lighting livable city workshop, Glasgow 2013", The Architectural Journal, pp. 31-65.

\section{Corresponding author}

Marco Bevolo can be contacted at: marco.bevolo@gmail.com

For instructions on how to order reprints of this article, please visit our website: 